\title{
The ISN's programs for prevention of kidney disease
}

\author{
John H Dirks
}

In 2001, the executive of the International Society of Nephrology (ISN) declared a new global mission-prevention of chronic kidney disease. ${ }^{1}$ At this time, an ISN Research Committee, led by Giuseppe Remuzzi (Italy), had just convened, and a basic understanding of progression of chronic kidney disease had been established. This understanding was verified in clinical trials designed to reduce blood pressure, and thereby directly minimize glomerular pressure and the fibrosing effects of proteinuria. As a result, administration of renin-angiotensin blockers and other agents to ameliorate blood pressure and proteinuria is now recommended for contemporary management of patients with proteinuria and reduced glomerular filtration rates. All of these advances occurred amidst fears of a global epidemic of diabetes and hypertensive disease, when the prevalence was increasing at a particularly alarming rate in low and middle income countries.

Between 2001 and 2005, the ISN held a number of strategic conferences on the prevention of kidney disease, including two in Bellagio, Italy, supported by the Rockefeller Foundation. The theme of the first, in March 2004, was progression of chronic kidney disease. ${ }^{2}$ The second, held in December 2005, was entitled Prevention of vascular diseases in the emerging world: a multidisciplinary approach to global health equity. Delegates discussed the integrative nature of prevention of chronic vascular disorders such as diabetes, cardiovascular, kidney and atherosclerotic disease. During this period, the ISN also partnered with other organizations and convened to discuss prevention, in Hong Kong for Asia, Villarica (Chile) for Latin America, Delhi for India, and Amsterdam for Europe. A series of guidelines on who should be screened and who should be treated were developed and disseminated. ${ }^{3}$

In each of the past 2 years, the ISN's Commission for the Global Advancement of

\section{The ISN has \\ assumed a \\ leadership \\ role...that must \\ be maintained \\ into the next \\ generation \\ so that the \\ surge in the \\ prevalence of \\ kidney disease \\ is ameliorated}

J Dirks is President of ISN COMGAN, President of The Gairdner Foundation, Senior Fellow of Massey College, and Professor Emeritus of Medicine at the University of Toronto, Canada.

\section{Competing interests \\ The author declared he has no competing interests.}

www.nature.com/clinicalpractice doi:10.1038/ncpneph0071
Nephrology (COMGAN) has sponsored and supported more than 50 continuing medical education courses. These courses have included comprehensive instruction in prevention of chronic kidney disease, as well as acute renal failure and glomerular disease. ISN Fellowships have been awarded to those who will foster prevention in countries in which treatment for end-stage renal disease is limited or unavailable.

Education of primary care physicians has also been undertaken. The Bergamo group and the Research Committee of COMGAN led the development of a prototype program for screening and intervention (Program for Detection and Management of Chronic Kidney Disease, Hypertension, Diabetes and Cardiovascular Disease in Developing Countries [KHDC]). With the flexibility to be adapted to specific local conditions, the prototype program has now been applied in South Africa, Nepal, South China, South India, Bolivia, Mexico and Moldova. The scope of the program strategies encompasses primary prevention via weight control (diet and physical activity) and smoking cessation. Secondary prevention-through control of blood pressure, proteinuria, lipids, anemia, calcium-phosphate disorders-and prevention of tertiary complications in patients with end-stage renal disease, are also addressed.

The epidemic of chronic diseases is the greatest health challenge of the $21^{\text {st }}$ century. The ISN has assumed a leadership role in addressing this challenge that must be maintained into the next generation so that the surge in the prevalence of kidney disease is ameliorated to the benefit of individual patients and the health budgets of all nations.

Supplementary information, in the form of a reference list, is available on the Nature Clinical Practice Nephrology website. 